\title{
APICE. UN PROGRESO EN EL CONTROL DE CALIDAD DE LA FORMACIÓN DE ESPECIALISTAS
}

\author{
APICE. A progress in quality control of the training specialists
}

Como es sabido, de acuerdo a la ley de aseguramiento de la calidad de la Educación Superior (2006) y la consiguiente constitución de la CNA y las agencias de ella dependientes, se dio comienzo a la acreditación de la educación en la formación de profesionales de la salud, tanto de pregrado, postgrado y postítulo, especificamente en este último punto, de los programas de formación de especialistas médicos. Se debe entender por acreditación al proceso a que se someten las instituciones de Educación Superior autónomas del país, así como las carreras de pregrado, programas de postgrado (doctorados y magísteres) y las especialidades médicas que ellas imparten, con el objeto de contar con una evaluación y certificación de calidad de sus procesos y resultados. En enero de 2009, de acuerdo a las disposiciones legales vigentes, la CNA autorizó a la Agencia Acreditadora de Programas y Centros Formadores de Especialistas Médicos (APICE) para comenzar su labor. Esta es una institución de derecho privado, sin fines de lucro, de carácter nacional, autorizada y supervisada por la CNA, cuyo objetivo es promover y garantizar la calidad del proceso formativo de los especialistas médicos en los programas universitarios existentes en el país. La institución consta de un directorio, consejos de acreditación, pares evaluadores (que reciben talleres de formación periódicos) y un secretario ejecutivo con su estructura de administración. Debe destacarse que la acreditación de los programas es realizada exclusivamente por el consejo de acreditación correspondiente y el Directorio no tiene papel alguno en esta importante decisión, salvo tomar conocimiento y remitir el resultado a la CNA.

Como era de esperar, el comienzo de este trabajo fue relativamente lento, en especial por la demora y cierta reticencia de algunas universidades para someter sus programas a esta evaluación, siendo los primeros años difíciles para APICE, porque su financiamiento depende en forma fundamental de su actividad. Sin embargo, a medida que el tiempo fue asentando la necesidad de esta acreditación, tanto en el proceso de desarrollo universitario, como en las disposiciones legales que reconocen al egresado como especialista sólo si el programa formativo está debidamente acreditado, en los últimos años se ha observado un incremento notable de la demanda y de la actividad acreditadora. En el país existen 15 universidades que tienen un total de 240 programas de postítulo de especialidades médicas. A la fecha, APICE lleva un total de 125 de estos programas ya sea con acuerdo de acreditación emitido o en proceso para ello, con un incremento progresivo de este número.

La agencia APICE original fue constituida por 4 socios: la ASOFAMECH, la ASOCIMED, el COLEGIO MÉDICO DE CHILE y la ACADEMIA DE MEDICINA, como socio honorario.

Recientemente la ASOFAMECH se retiró de la propiedad de la agencia, con lo que el número de entidades socias se redujo a tres. Este retiro contribuye, de alguna manera, a disminuir los riesgos de potenciales conflictos de interés en las decisiones de la agencia.

Previo al inicio del proceso de acreditación se fijaron los estándares básicos que deben cumplir todos los programas, manteniendo la autonomía de cada uno para características particulares. Los egresados de programas acreditados son reconocidos por CONACEM y otras instituciones y puede inscribirse como especialistas formales en el Registro de la Intendencia de Prestadores. Así, APICE cumple con la ley destinada a mejorar la calidad de la educación superior en el pais.

Dr. Osvaldo Llanos L. Presidente de APICE 